\title{
Karakteristik Morfometri Kambing Peranakan Etawah Betina pada Umur Berbeda di Kecamatan Boyolangu Kabupaten Tulungagung
}

\section{(Morfometric Characteristics of Peranakan Etawah Female in Different Age at Boyolangu District Tulungagung Regency)}

\author{
Nugraha CD, Iqbal M, Suyadi \\ Research Group Genomics and Proteomics, Fakultas Peternakan, Universitas Brawijaya \\ suyadi@ub.ac.id
}

\begin{abstract}
This study aimed to determine the characteristics of quantitative and qualitative of Peranakan Etawah goat (PE) female at Boyolangu, Tulungagung Regency. The research method was a purposive sampling. The material used were 75 female PE goats with ages PI0 and PI1. Quantitative data included body weight (BW), chest circumference (CC), chest (CH), height (HG), body length (BL), hip height (HH), hind limb length (HLL), chest width (CW), hip width (HW), front foot length (FFL) and tail length (TL) then grouped into two, namely age PI0 and PI1. Qualitative data included the color of the body and head. Quantitative data was analyzed by unpaired sample T-test. Qualitative data were calculated the frequency of the phenotype. Correlations between vital statistics and body weight using Pearson correlation (r). Quantitative characteristics of BW, CC, CH, HG, BL, HH and HLL were higher at PI1 age $(\mathrm{P}<0.05)$, but $\mathrm{CW}$, HW, FFL and TL were not significantly $(\mathrm{P}>0.05)$. Qualitative characteristics showed that female PE goat had the dominant color of combination brownblack-white. The highest correlation was chest circumference and body weight $(r=0.91)$. It was concluded that PE female goats of PI1 age had higher quantitative traits than PI0 ages. The qualitative of $\mathrm{PE}$ female goats was dominated by the brown-black-white color combination.
\end{abstract}

Key words: Peranakan Etawah goat, morphometric, quantitative traits, qualitative traits, correlations

\begin{abstract}
ABSTRAK
Penelitian ini bertujuan mengetahui karakteristik sifat kuantitatif dan kualitatif serta menduga bobot badan menggunakan statistik vital kambing Peranakan Etawah (PE) betina di Kecamatan Boyolangu, Kabupaten Tulungagung. Materi penelitian menggunakankambing PE betina sebanyak 75 ekor dengan umur PI0 dan PI1. Metode yang digunakan dalam penelitian ini adalah purposive sampling. Data kuantitatif meliputi bobot badan (BB), lingkar dada (LD), dalam dada (DD), tinggi badan (TB), panjang badan (PB), tinggi pinggul (TP), panjang kaki belakang (PKB), lebar dada (LDD), lebar pinggul (LP), panjang kaki depan (PKD) dan panjang ekor (PEK) dikelompokkan berdasarkan umur PI0 dan PI1. Data kualitatif meliputi warna tubuh, kepala dan telinga. Sifat kuantitatif dianalisis uji-T sampel tidak berpasangan. Sifat kualitatif dihitung frekuensi fenotipnya. Korelasi antara statistik vital terhadap BB menggunakan korelasi pearson dan analisis regresi linear untuk menghitung rumus pendugaan antar variabel. Sifat kuantitatif BB, LD, DD, TB, PB, TP dan PKB lebih tinggi pada umur PI1 $(\mathrm{P}<0,05)$, namun LDD, LP, $\mathrm{PKD}$ dan PEK tidak berbeda signifikan $(\mathrm{P}>0,05)$ antara umur PI0 dan PI1. Sifat kualitatif warna tubuh, dan kepala kambing PE betina paling banyak adalah kombinasi coklat-hitam-putih sebesar 58,7\% dan $45,4 \%$. Nilai korelasi tertinggi yaitu LD
\end{abstract}


terhadap BB sebesar 0,91. Kambing PE betina umur PI1 memiliki sifat kuantitatif yang lebih tinggi dibandingkan umur PI0. Sifat kualitatif kambing PE betina didominasi oleh kombinasi warna coklat-hitam-putih. Lingkar dada merupakan statistik vital terbaik untuk menduga bobot badan.

Kata kunci: Kambing PE betina, morfometrik, sifat kuantitatif, sifat kualitatif, korelasi

\section{PENDAHULUAN}

Kambing memberikan peran cukup besar bagi masyarakat terhadap pendapatan utama sebagai peternak kecil. Usaha peternakan kambing menjadi salah satu usaha peternakan yang banyak dikembangkan di seluruh Indonesia. Provinsi Jawa Timur menempati urutan kedua dengan jumlah populasi ternak kambing tertinggi. Rata-rata jumlah populasi tahun 2017 sebanyak 3.328.928 ekor (Ditjen PKH 2017). Potensi ini perlu dikembangkan sebagai sentra usaha peternakan kambing bagi peternak.

Pengembangan kambing oleh peternak kebanyakan kambing jenis Peranakan Etawah (PE) karena memiliki banyak keunggulan. Kambing PE memiliki keunggulan yaitu cepat berkembang biak dan mudah beradaptasi dengan pakan yang tersedia (Nasich 2011). Kambing PE mudah dalam pemasarannya karena lebih banyak diminati masyarakat. Kambing PE memiliki karakteristik sifat yang berbeda-beda antar individu. Peternak pada umumnya melihat karakteristik kambing PE dari hal yang paling mudah diingat misalnya warna tubuh, postur tubuh dan bobot badan. Saat ini penelitian tentang identifikasi morfometrik pada kambing PE khususnya betina masih sangat terbatas. Informasi yang terkait dengan keragaman genetik belum tersedia dengan lengkap sehingga program seleksi dan pemuliaan belum terarah mengakibatkan produktivitas sangat beragam.

Seleksi kambing betina penting untuk dipersiapkan menjadi indukan yang unggul. Seleksi induk dapat dilihat dengan pendekatan performan ukuran tubuh atau morfometrik (Purwanti et al. 2019). Perlu dilakukan penelitian dengan mengkaji ukuran tubuh yang lebih lengkap, tentunya akan bermanfaat dalam pembendaharaan ilmiah mengenai morfometrik kambing PE betina. Kajian morfometrik bertujuan untuk mendapatkan data sifat atau deskripsi karakterisasi ternak kambing dalam membedaan fenotipe dan seberapa besar keragaman genetik pada suatu wilayah tertentu (Adiati \& Priyanto 2011). Sedangkan sifat kualitatif pada kambing yang biasa diamati meliputi warna tubuh dominan dan warna kepala (Doloksaribu et al. 2006; Sodiq 2009).

Berdasarkan latar belakang ini, diperlukan kajian karakteristik sifat morfometrik sebagai informasi dalam meningkatkan performa kambing PE di Kecamatan Boyolangu Kabupaten Tulungagung. Tujuan dari penelitian ini adalah untuk mengetahui karakteristik sifat kuantitatif dan kualitatif pada kambing PE betina umur PI0 dan PI1, serta untuk menduga bobot badan menggunakan statistik vital kambing PE betina. Hasil dari penelitian ini nantinya dapat memudahkan seleksi pembibitan dan memberikan ciri khas yang jelas pada kambing PE di Kecamatan Boyolangu, Kabupaten Tulungagung.

\section{MATERI DAN METODE}

Penelitian ini dilaksanakan bulan Januari hingga Februari 2019. Lokasi penelitian dilaksanakan di desa Kendalbulur dan desa Waung, kecamatan Boyolangu, kabupaten Tulungagung. Materi yang digunakan yaitu kambing PE betina sebanyak 75 ekor yang terdiri atas umur 8-12 bulan (PI0) dan umur >12-14 bulan (PI1). 
Metode yang digunakan dalam penelitian ini adalah purpose sampling. Data kuantitatif diperoleh dengan cara mengukur anggota tubuh meliputi lingkar dada (LD) diukur melingkar dada tepat dibelakang kaki depan, dalam dada (DD) diukur dari titik tertinggi pundak dan tulang dada, lebar data (LDD) diukur dari sendi bahu (Os scapula) kiri dan kanan, tinggi badan (TB) diukur tegak lurus dari tanah sampai tulang punggung (Vetebrae thoracalis), panjang badan (PB) diukur jarak antara bahu (Tuberculum humerus lateralis) sampai tulang duduk (Tuberculum ischiadium), tinggi pinggul (TP) diukur dari pinggul secara tegak lurus ke tanah, lebar pinggul (LP) diukur antara kedua sendi pinggul, panjang kaki depan (PKD) diukur dari bagian tulang yang menonjol di bagian depan dada sampai tanah, panjang kaki belakang (PKB) diukur dari ujung kaki bawah sampai tonjolan tulang tapis, panjang ekor (PEK) diukur dari pangkal ekor hingga ujung ekor. Data kuantitatif yang didapat kemudian dikelompokkan menjadi dua kelompok umur yaitu PI0 (<12 bulan) dan PI1 (12-18 bulan). Data kualitatif didapatkan melalui pengamatan dan pencatatan meliputi warna tubuh, kepala dan telinga.

Sifat kuantitatif dianalisis uji-t sampel tidak berpasangan (unpaired comparation) kemudian dianalisis secara deskriptif. Sifat kualitatif dihitung frekuensi fenotipnya. Korelasi antara lingkar dada, panjang badan, tinggi badan terhadap bobot badan menggunakan korelasi pearson (r) dan analisis regresi linear digunakan untuk menghitung rumus pendugaan antar variabel.

\section{HASIL DAN PEMBAHASAN}

\section{Karakteristik sifat kuantitatif kambing peranakan etawah betina}

Berdasarkan hasil penelitian ini, rataan bobot badan dan statistik vital kambing PE betina pada umur PI0 dan PI1 dapat dilihat pada Tabel 1. Tabel 1 menunjukkan bahwa bobot badan, lingkar dada, dalam dada, tinggi badan, panjang badan, tinggi pinggul dan panjang kaki belakang meningkat seiring dengan bertambahnya umur $(\mathrm{P}<0,05)$. Ukuran statistik vital (lingkar dada, dalam dada, tinggi badan, panjang badan, tinggi pinggul dan panjang kaki belakang) kambing PE betina umur PI1 lebih besar dibandingkan dengan kambing PE betina umur PI0.

Peningkatan ukuran statistik vital secara umum dalam penelitian ini masih lebih rendah dibandingkan dengan Badan Standardisasi Nasional (2015) yang menyebutkan bahwa kambing PE betina umur 8-12 bulan memiliki tinggi badan, panjang badan, lingkar dada dan bobot badan berturut-turut sebesar $56 \mathrm{~cm}, 51 \mathrm{~cm}, 52 \mathrm{~cm}$ dan $19 \mathrm{~kg}$. Umur 12-18 bulan memiliki tinggi badan, panjang badan, lingkar dada dan bobot badan berturut-turut sebesar $65 \mathrm{~cm}, 62 \mathrm{~cm}, 66 \mathrm{~cm}$ dan $26 \mathrm{~kg}$. Hasil penelitian ini kambing PE betina umur PI 0 memiliki tinggi badan, panjang badan, lingkar dada dan bobot badan berturut-turut sebesar 49,163 cm; 50,325 cm; 52,350 cm dan 12,725 kg. Umur PI 1 memiliki tinggi badan, panjang badan, lingkar dada dan bobot badan berturut-turut sebesar 54,100 cm; 56,457 cm; 57,729 cm dan 15,714 kg. Rendahnya hasil ini dibandingkan standar nasional dikarenakan kualitas genetik kambing PE betina yang dipelihara peternak masih sangat bervariasi. 
Tabel 1. Rata-rata bobot badan dan statistik vital kambing PE betina pada umur PI0 dan umur PI1

\begin{tabular}{lcc}
\hline \hline \multirow{2}{*}{ Karakteristik } & \multicolumn{2}{c}{ Umur } \\
\cline { 2 - 3 } & PI 0 (n=40) & PI 1 (n=35) \\
\hline Bobot badan (kg) & $12,725 \pm 1,92^{\mathrm{a}}$ & $15,714 \pm 1,11^{\mathrm{b}}$ \\
Lingkar dada (cm) & $52,350 \pm 3,31^{\mathrm{a}}$ & $57,729 \pm 2,86^{\mathrm{b}}$ \\
Dalam dada (cm) & $23,675 \pm 2,99^{\mathrm{a}}$ & $25,714 \pm 3,14^{\mathrm{b}}$ \\
Lebar dada (cm) & $17,650 \pm 2,29$ & $18,414 \pm 3,45$ \\
Tinggi badan (cm) & $49,163 \pm 3,74^{\mathrm{a}}$ & $54,100 \pm 3,02^{\mathrm{b}}$ \\
Panjang badan (cm) & $50,325 \pm 4,38^{\mathrm{a}}$ & $56,457 \pm 4,17^{\mathrm{b}}$ \\
Tinggi pinggul (cm) & $53,488 \pm 5,03^{\mathrm{a}}$ & $57,800 \pm 3,59^{\mathrm{b}}$ \\
Lebar pinggul (cm) & $17,875 \pm 2,70$ & $19,200 \pm 3,23$ \\
Panjang kaki depan (cm) & $32,525 \pm 4,99$ & $32,686 \pm 2,55$ \\
Panjang kaki belakang (cm) & $36,800 \pm 3,20^{\mathrm{a}}$ & $38,514 \pm 3,08^{\mathrm{b}}$ \\
Panjang ekor (cm) & $12,375 \pm 1,64$ & $12,886 \pm 1,62$ \\
\hline Ke
\end{tabular}

Keterangan: Superskrip yang berbeda pada baris yang sama menunjukkan perbedaan yang signifikan $(\mathrm{P}<0,05)$

Tabel 1 menunjukkan bahwa perbedaan umur tidak signifikan meningkatkan lebar dada, lebar pinggul, panjang kaki depan dan panjang ekor $(\mathrm{P}>0,05)$. Hal ini dipengaruhi oleh faktor lingkungan dan sistem pemeliharaan (Abidin 2008; Permatasari et al. 2013). Sistem manajemen pemeliharaan yang buruk dengan memberi pakan kualitas rendah menjadikan kambing tidak berkembang dengan baik walaupun kambing mempunyai genetik pertumbuhan yang baik, sebaliknya peternak yang memberikan pakan dengan kualitas dan kuantitas yang baik maka kambing akan tumbuh dengan baik (Nasich 2011).

Performans bobot badan kambing PE betina umur PI1 yaitu 15,714 $\pm 1,11 \mathrm{~kg}$ lebih besar dibandingkan dengan kambing PE betina umur PI0 yaitu 12,725 $\pm 1,92 \mathrm{~kg}$. Hal ini juga memiliki kesamaan dengan penelitian Rasminati (2013) menunjukkan bahwa bobot badan kambing PE betina indukan sebesar $40 \mathrm{~kg}$, lebih tinggi dibandingkan kambing dara sebesar 27,5 kg. Perbedaan bobot badan kambing PE betina berdasarkan umur yang berbeda ini disebabkan karena faktor pertumbuhan. Meningkatnya umur kambing akan diikuti dengan peningkatan bobot badan. Bukhori et al. (2017) menyatakan bobot badan dan ukuran tubuh yang semakin meningkat disebabkan karena ternak berada pada masa pertumbuhan. Pertumbuhan adalah proses pertambahan berat badan, otot dan ukuran tubuh seiring meningkatnya umur ternak (Sutiyono et al. 2006; Nugraha et al. 2015). Pertumbuhan yang ideal pada kondisi lingkungan yang baik akan membentuk kurva sigmoid (Karnaen 2007).

\section{Karakteristik sifat kualitatif kambing peranakan etawah betina}

Berdasarkan hasil penelitian, karakteristik warna tubuh dan kepala pada kambing Peranakan Etawah (PE) betina dapat dilihat pada Tabel 2. Tabel 2 menunjukkan bahwa kambing PE dengan karakteristik persentase tertinggi ditemukan pada kombinasi warna coklat-hitam-putih sebesar 58,7\% sedangkan pada kepala dan telinga sebesar 45,4\%. Kambing PE di desa Kendalbulur dan desa Waung kecamatan Boyolangu, kabupaten 
Tulungagung didominasi oleh kombinasi warna coklat-hitam-putih. Penelitian Rasminati (2013) pada kambing PE di daerah gunung menyatakan bahwa warna kambing PE didiminasi warna hitam-putih sebesar 93,10\%. Badan Standarisasi Nasional (2015) tentang Penetapan Standar Nasional Indonesia SNI 7352.1:2015 bahwa persyaratan kualitatif kambing PE yaitu warna bulu putih, hitam, coklat atau kombinasinya.

Tabel 2. Karakteristik pola warna tubuh, kepala dan telinga pada kambing Peranakan Etawah (PE) Betina

\begin{tabular}{lcccc}
\hline \hline \multirow{2}{*}{ Karakteristik } & \multicolumn{2}{c}{ Warna tubuh } & \multicolumn{2}{c}{ Warna kepala dan telinga } \\
\cline { 2 - 5 } & $\mathrm{n}$ & Nilai (\%) & $\mathrm{n}$ & Nilai (\%) \\
\hline Putih & 1 & 1,3 & 1 & 1,3 \\
Coklat & 6 & 8 & 6 & 8 \\
Hitam & 4 & 5,3 & 4 & 5,3 \\
Coklat-putih & 12 & 16 & 17 & 22,7 \\
Coklat-hitam & 2 & 2,7 & 6 & 8 \\
Hitam-putih & 6 & 8 & 7 & 9,3 \\
Coklat-hitam-putih & 44 & 58,7 & 34 & 45,4 \\
Total & 75 & 100 & 75 & 100 \\
\hline
\end{tabular}

Kombinasi warna coklat-hitam-putih paling banyak ditemukan di bagian dada, pinggul, kaki dan kepala. Kombinasi warna coklat-putih dan hitam-putih banyak ditemukan di bagian perut samping dan perut bawah. Kombinasi warna coklat-hitam pada bagian punggung dan bulu kaki belakang, sedangkan bagian ekor didominasi warna polos. Kombinasi yang berbeda ini dipengaruhi oleh gen-gen yang berbeda tetapi bekerjasama dengan gen warna dasar (Mulliadi 1996). Destomo et al. (2017) menyatakan bahwa pada ternak kambing pigmen yang mengatur warna tubuh yaitu eumelamin dan pheomelamin. Eumelamin menyebabkan warna black bluegreen dan chocolate brown sedangkan pheomelamin menyebabkan warna tan dan merah. Warna putih merupakan yang tidak berpigmen. Kambing PE betina di kecamatan Boyolangu Kabupaten Tulungagung memiliki gen warna kombinasi coklat-hitam-putih yang paling banyak.

\section{Korelasi dan persamaan regresi antara statistik vital dengan bobot badan pada kambing peranakan etawah betina}

Nilai korelasi (r), koefisien determinasi $\left(\mathrm{R}^{2}\right)$ dan persamaan regresi antara statistik vital (X) dengan bobot badan (Y) kambing PE betina dapat dilihat pada Tabel 3. Tabel 3 menunjukkan bahwa variabel $x$ (LD, PB, TB) berkorelasi terhadap variabel y (BB). Nilai korelasi tertinggi pada lingkar dada terhadap bobot badan $(\mathrm{r}=0,91)$ dan terendah pada tinggi badan terhadap bobot badan $(\mathrm{r}=0,63)$, sedangkan nilai korelasi panjang badan terhadap bobot badan $(\mathrm{r}=0,69)$. Hal ini lebih tinggi dibandingkan hasil penelitian kambing lokal India yaitu kambing Rohilkhand korelasi bobot badan dengan lingkar dada sebesar 0,76; panjang badan 0,55 dan tinggi badan 0,66 (Fahim et al. 2013).

Lingkar dada mempunyai hubungan yang paling kuat terhadap bobot badan. Semakin tinggi ukuran lingkar dada maka akan meningkatkan bobot badan. Raja et al. (2013) menyatakan bahwa ukuran lingkar dada memiliki hasil yang paling baik dan nilai korelasi yang tinggi dibandingkan dengan ukuran tubuh lainnya, seperti panjang tubuh 
dan tinggi badan. Nilai korelasi yang tinggi dapat digunakan untuk menduga bobot badan pada kambing $\mathrm{PE}$ betina. LD, PB, TB dapat digunakan untuk menduga bobot badan $(\mathrm{P}<0,05)$ dengan persamaan regresi berturut-turut yaitu $\mathrm{Y}=30,696+1,711 \mathrm{X} ; \mathrm{Y}=29,832$ $+1,654 \mathrm{X}$ dan $\mathrm{Y}=34,262+1,218 \mathrm{X}$.

Tabel 3. Hubungan antara lingkar dada, tinggi badan, panjang badan terhadap bobot badan kambing PE betina

\begin{tabular}{llllll}
\hline \hline Variabel & $\mathrm{n}$ & $\mathrm{r}$ & $\mathrm{R}^{2}$ & Persamaan Regresi & P Value \\
\hline LD - BB & 75 & 0,91 & 0,828 & $\mathrm{Y}=30,696+1,711 \mathrm{X}$ & 0,000 \\
PB - BB & 75 & 0,69 & 0,471 & $\mathrm{Y}=29,832+1,654 \mathrm{X}$ & 0,000 \\
TB - BB & 75 & 0,63 & 0,399 & $\mathrm{Y}=34,262+1,218 \mathrm{X}$ & 0,000 \\
\hline
\end{tabular}

Keterangan: $\mathrm{LD}=$ Lingkar Dada; $\mathrm{PB}=$ Panjang Badan; $\mathrm{TB}=$ Tinggi Badan; $\mathrm{BB}=$ Bobot Badan; PI = Permanent Insisipi

Tabel 3 menunjukkan bahwa nilai tertinggi koefisien determinasi yaitu antara lingkar dada dengan bobot badan dengan nilai 0,828 artinya 82,8\% dari bobot badan dipengaruhi oleh lingkar dada. Ukuran lingkar dada bertambah mengikuti pertumbuhan dan perkembangan jaringan otot yang ada di tulang rusuk atau daerah dada (Setiawati et al. 2013). Koefisien determinasi panjang badan dengan bobot badan yaitu 0,471 artinya 47,1\% dari bobot badan dipengaruhi oleh panjang badan. Ukuran panjang badan merupakan pencerminan pertumbuhan dan perkembangan tulang belakang (Trisnawanto et al. 2012). Koefisien determinasi tinggi badan dengan bobot badan yaitu 0,399 artinya 39,9\% dari bobot badan dipengaruhi oleh tinggi badan. Tinggi badan sangat berkaitan dengan pertumbuhan tulang kaki depan. Sutiyono et al. (2006) menyatakan bahwa tulang penyusun kaki depan mengalami pertumbuhan lebih awal sesuai dengan fungsinya yaitu untuk menyangga tubuh. Faktor lain yang mempengaruhi produktivitas ternak adalah faktor genetik dan faktor lingkungan, faktor lingkungan antara lain adalah suhu, kelembaban, angin dan radiasi matahari (Sumartono et al. 2016).

\section{KESIMPULAN}

Berdasarkan hasil penelitian dapat disimpulkan bahwa kambing PE betina di desa Kendalbulur dan desa Waung kecamatan Boyolangu, kabupaten Tulungagung umur PI1 memiliki sifat kuantitatif yang lebih tinggi dibandingkan umur PI0. Sifat kualitatif kambing PE betina didominasi oleh kombinasi warna coklat-hitam-putih. Lingkar dada merupakan statistik vital terbaik untuk menduga bobot badan kambing PE betina.

Hasil dari penelitian ini dapat digunakan sebagai pedoman potensi bibit kambing PE betina di kecamatan Boyolangu, kabupaten Tulungagung sehingga program kebijakan dalam usaha pembibitan akan lebih tepat dan terarah.

\section{DAFTAR PUSTAKA}

Abidin Z. 2008. Penggemukan sapi potong. Jakarta (Indonesia): PT Agro Media Pustaka.

Adiati U, Priyanto D. 2011. Karakteristik morfologi kambing pe di dua lokasi sumber bibit. Prosiding Seminar Nasional Teknologi Peternakan dan Veteriner. Bogor (Indonesia): Pusat Penelitian dan Pengembangan Peternakan. hlm. 472-478. 
Badan Standardisasi Nasional Indonesia. 2015. Bibit kambing Peranakan Etawah (PE). Jakarta (Indonesia): Badan Standardisasi Nasional.

Bukhori I, Aka R, Saili T. 2017. Pola pertumbuhan kambing kacang jantan di Kabupaten Konawe Selatan. J Ilmu Teknologi Peternakan Tropis. 4:34-41.

Destomo A, Batubara A, Elieser S. 2017. Characteristics of qualitative traits of local goat in Bengkalis regency. Prosiding Seminar Nasional Teknologi Peternakan dan Veteriner. Bogor (Indonesia): Pusat Penelitian dan Pengembangan Peternakan. hlm. 10:303-314.

Direktorat Jenderal Peternakan dan Kesehatan Hewan. 2017. Statistik Peternakan dan Kesehatan Hewan. Jakarta (Indonesia): Direktorat Jenderal Peternakan dan Kesehatan Hewan.

Doloksaribu M, Batubara A, Elieser S. 2006. Characteristic morfologi of local specific goat in samosir districts north sumatra. Prosiding Seminar Nasional Teknologi Peternakan dan Veteriner. Bogor (Indonesia): Pusat Penelitian dan Pengembangan Peternakan. hlm. 544549.

Fahim A, Patel BHM, Rijasnaz VV. 2013. Relationship of body weight with linear body measurements in Rohilkhand local goats. Indian J Anim Res. 47:521-526.

Karnaen. 2007. Model kurva pertumbuhan pra sapih dari sapi Madura betina dan jantan. Jurnal Ilmu Ternak. 7:48-51.

Mulliadi D. 1996. Sifat fenotipik domba Priangan di Kabupaten Pandeglang dan Garut [Disertasi]. [Bogor (Indonesia)]: Institut Pertanian Bogor.

Nasich M. 2011. Produktivitas kambing hasil persilangan antara pejantan Boer dengan induk lokal (PE) periode prasapih. J Ternak Tropika. 12:56-62.

Nugraha CD, Maylinda S, Nasich M. 2015. Karakteristik sapi Sonok dan sapi Kerapan pada umur yang berbeda di Kabupaten Pamekasan Pulau Madura. J Ternak Tropika. 16:55-60.

Permatasari T, Kurnianto E, Purbowati E. 2013. Hubungan antara ukuran ukuran tubuh dengan bobot badan pada Kambing Kacang di Kabupaten Grobongan Jawa Tengah. Anim Agric J. 2:28-34.

Purwanti D, Setiatin ET, Kurnianti E. 2019. Morfometrik tubuh kambing Peranakan Ettawa pada berbagai paritas di Balai Pembibitan dan Budidaya Ternak Terpadu Kabupaten Kendal. J Ilmu-ilmu Peternakan. 29:15-23.

Raja TV, Venkatachalapathy RT, Kannan A, Bindu KA. 2013. Determination of best-fifted regression model for prediction of body weight in attappady Black Goats. Glob J Anim Breeding Genet. 1:020-025.

Rasminati N. 2013. Grade kambing Peranakan Ettawa pada kondisi wilayah yang berbeda. Sains Peternakan. 11:43-48.

Setiawati T, Sambodho P, Sustiah A. 2013. Tampilan bobot badan dan ukuran tubuh kambing dara Peranakan Ettawa akibat pemberian ransum dengan suplementasi urea yang berbeda. J Anim Agric. 2:8-14.

Sodiq A. 2009. Karakterisasi sumberdaya kambing lokal khas Kejobong di Kabupaten Purbalingga Propinsi Jawa Tengah. Agripet. 9:31-37.

Sumartono, Hartutik, Nuryadi, Suyadi. 2016. Productivity index of Etawah Crossbred goats at different altitude in Lumajang District, East Java Province, Indonesia. IOSR J Agric Vet Sci. 9:24-30.

Susanto AD, Soetriono, Supriono A. 2017. Analisis perwilayahan dan strategi pengembangan peternakan kambing di Kabupaten Lumajang. Sorot. 12:107-120. 
Sutiyono B, Widyani NJ, Purbowati E. 2006. Studi performance induk kambing Peranakan Etawa berdasarkan jumlah anak sekelahiran di Desa Banyuringin Kecamatan Singosari Kabupaten Kendal. Prosiding Seminar Nasional Teknologi Peternakan dan Veteriner. Bogor (Indonesia): Pusat Penelitian dan Pengembangan Peternakan. hlm. 537-543.

Trisnawanto R, Adiwinarti, Dilaga WS. 2012. Hubungan antara ukuran-ukuran tubuh dengan bobot badan Dombos jantan. J Anim Agric. 1:653-668. 